\title{
Differential Pulse Anodic Voltammetric Determination of the Pharmaceutical Compound Pramipexole Dihydrochloride in its Tablets
}

\author{
Sayed I.M. Zayed, ${ }^{a, b,{ }^{*}}$ Rasha G.A. Oraby, ${ }^{a}$ Ashwak E.A. EI Thobety ${ }^{a}$ \\ and Mona M. Abdel-Moaty ${ }^{c}$ \\ ${ }^{a}$ Chemistry Department, Faculty of Science, Taif University, 888-Taif, KSA \\ ${ }^{b}$ Faculty of Industrial Education, Beni-Suef University, Beni-Suef, Egypt \\ ${ }^{c}$ National Organization for Drug Control and Research, Giza, Egypt
}

Received January 12, 2017; accepted April 2, 2017

\begin{abstract}
The electrochemical behavior of pramipexole dihydrochloride was studied at carbon paste electrodes in $0.04 \mathrm{M}$ Britton-Robinson buffer of $\mathrm{pH} 6.08$, using cyclic and differential pulse voltammetric techniques. The oxidation of pramipexole dihydrochloride is an irreversible diffusion-controlled process. A differential pulse anodic voltammetric procedure has been developed for determination of the drug over the concentration range of $1.20-8.23 \mu \mathrm{g} / \mathrm{mL}$, with detection and quantification limits of 0.21 and $0.68 \mu \mathrm{g} / \mathrm{mL}$, respectively. The proposed method was successfully applied for the determination of the drug in its commercial tablets.
\end{abstract}

Keywords: pramipexole dihydrochloride, differential pulse anodic voltammetry, carbon paste electrode, pharmaceutical formulation.

\section{Introduction}

The structural formula of pramipexole dihydrochloride monohydrate, (S)-2amino-4, 5, 6.7-tetrahydro-6-(propylamino) benzothiazole dihydrochloride, monohydrate [191217-81-9] is as given in Scheme 1. It is a non-ergot dopamine agonist with actions similar to those of bromocriptine. It is similarly used in the management of Parkinson's disease, either alone or as an adjunct to levodopa. It is also used for the treatment of moderate to severe restless legs syndrome [1].

Various analytical methods have been reported in literature for determination of pramipexole dihydrochloride, including high performance liquid chromatography (HPLC) [2-12], high performance thin layer chromatography [13], liquid chromatography tandem mass spectrometry [14, 15], gas chromatography mass spectrometry GC/MS [16], spectrophotometry [17-24], and potentiometry [25,

\footnotetext{
*Corresponding author. E-mail address: simzayed2011@hotmail.com
} 
26]. Recently, voltammetric determination of this drug using glassy carbon electrodes was reported [27-30]. The present work aimed to study the voltammetric behaviour and make an assay with pramipexole dihydrochloride at carbon paste electrode, using cyclic and differential pulse voltammetry.<smiles>CCCNC1CCc2nc(N)sc2C1</smiles>

Scheme 1. Structural formula of pramipexole dihydrochloride monohydrate.

\section{Experimental}

\section{Reagents and materials}

All chemicals were of analytical grade. Double distilled water was used throughout all experiments. Pure grade pramipexole dihydrochloride monohydrate and the Ramixole pharmaceutical preparation (1 mg pramipexole dihydrochloride monohydrate/tablet) were kindly supplied by EVA Pharma for Pharmaceuticals and Medical Appliances, Cairo, Egypt; graphite powder (1-2 $\mu \mathrm{m})$ was from Aldrich, and paraffin oil was from BDH. As a supporting electrolyte, a series of $0.04 \mathrm{M}$ Britton-Robinson (BR) buffers of $\mathrm{pH} 2.0-11.5$ (a mixture of each of acetic, orthophosphoric and boric acids), adjusted to the required $\mathrm{pH}$ with $0.2 \mathrm{M}$ sodium hydroxide, was prepared.

\section{Apparatus}

All voltammetric measurements were performed using a Metrohm 797 VA Computrace (Herisau, Switzerland) equipped with a Metrohm VA 694 stand. The three electrodes assembly cell consisted of a carbon paste electrode (CPE) as working electrode, an $\mathrm{Ag} / \mathrm{AgCl}$ in $3 \mathrm{~mol} / \mathrm{L} \mathrm{KCl}$ (Metrohm 6.0728.000) as a reference electrode, and a piece of platinum wire (Metrohm 6.0343.000) as an auxiliary electrode. The $\mathrm{pH}$ measurements were carried out with a Hanna $\mathrm{pH} 211$ microprocessor $\mathrm{pH}$ meter.

\section{Preparation of the carbon paste electrode}

The carbon paste was prepared by thoroughly mixing $5 \mathrm{~g}$ of graphite powder with $1.8 \mathrm{~mL}$ of paraffin oil in a mortar with a pestle. The carbon paste was packed into the hole of the electrode body and smoothed on a piece of clean paper until it had a shiny appearance. The electrode body was constructed by pressing a small rod of stainless-steel (diameter $2 \mathrm{~mm}$ ) inside a micropipette tip ( $1 \mathrm{~mL}$ volume capacity), leaving a space at the surface tip of approximately 1 $\mathrm{mm}$ for housing the carbon paste; a thin wire was inserted through the opposite end to establish electrical contact [31]. The carbon paste electrode was immersed in the supporting electrolyte placed in the cell, and several sweeps were applied to obtain a low background current. 


\section{Procedure}

A $10 \mathrm{~mL} 0.04 \mathrm{M}$ Britton-Robinson buffer of $\mathrm{pH} 6.08$ solution was introduced into the voltammetric cell; then, a known amount of the drug solution was pipetted into the cell. The differential pulse technique was applied by scanning from 0 to $1.4 \mathrm{~V}$ with a scan rate of $50 \mathrm{mV} \mathrm{s}^{-1}$, and a pulse amplitude of $60 \mathrm{mV}$.

\section{Determination of pramipexole dihydrochloride monohydrate in Ramixole tablets}

Twenty tablets (each tablet contains $1 \mathrm{mg}$ of pramipexole dihydrochloride monohydrate) were accurately weighed and powdered in a mortar. The required amount from the crushed tablet powder was dissolved in about $30 \mathrm{~mL}$ of bidistilled water, and the mixture was filtered in a $100 \mathrm{~mL}$ measuring flask. The residue was three times washed with bi-distilled water, and the volume was completed to the mark by the same solvent. A $10 \mathrm{~mL}$ volume of $0.04 \mathrm{M}$ BrittonRobinson buffer of $\mathrm{pH} 6.08$ was introduced into the voltammetric cell, and a suitable volume of the above tablet solution was pipetted into the buffer in the voltammetric cell; the procedure is repeated as above described. The nominal content of the tablets is calculated using a standard addition technique.

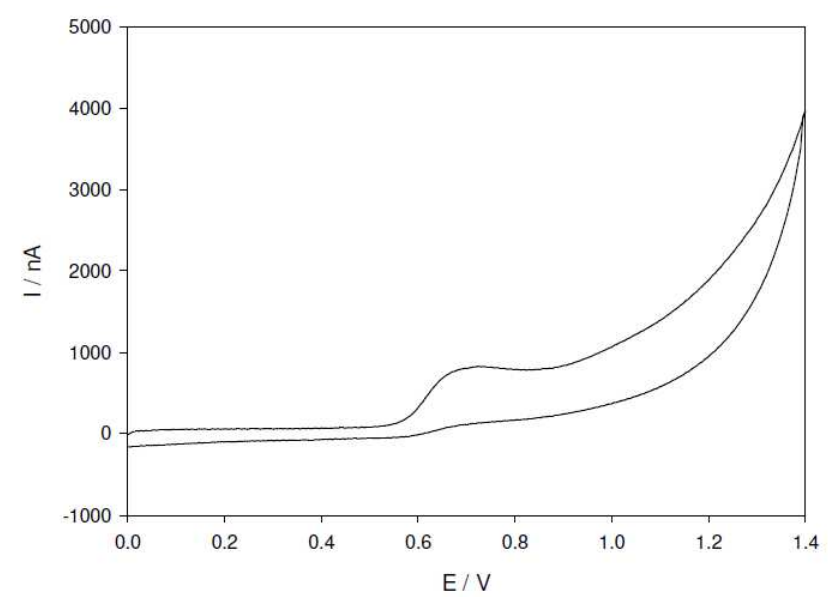

Figure 1. Cyclic voltammogram for $2.91 \times 10^{-5} \mathrm{M}$ solution of pramipexole dihydrochloride in a $0.04 \mathrm{M}$ Britton-Robinson buffer of $\mathrm{pH} 6.08$, and a scan rate of 50 $\mathrm{mV} \mathrm{s}^{-1}$ on a carbon paste electrode.

\section{Results and discussion}

\section{Voltammetric behavior}

Fig. 1 shows the cyclic voltammogram for $2.91 \times 10^{-5} \mathrm{M}$ pramipexole dihydrochloride in a $0.04 \mathrm{M}$ Britton-Robinson buffer of $\mathrm{pH} 6.08$, at a scan rate of $50 \mathrm{mV} \mathrm{s}^{-1}$. An oxidation peak appears at $0.681 \mathrm{~V}$; this may be due to the oxidation of the amino group of the benzothiazole ring of the drug molecule. No reduction peak is observed in the cathodic branch, which suggests that the process is irreversible. The effects of the scan rate on the peak current and peak potential were examined from 10 to $100 \mathrm{mV} \mathrm{s}^{-1}$. The plotting oxidation current against the square root of the scan rate gave a linear relation, which indicates that the oxidation of the drug is controlled by diffusion [32]. The controlled diffusion 
process was confirmed by the plotting logarithm of the peak current vs. the logarithm of the scan rate. This graph gives a straight line relation with a slope of 0.39 , which is close to the theoretically expected 0.5 value for a diffusioncontrolled process. The oxidation potential shifts to more +ve values by increasing the scan rate, which confirms the irreversibility of the oxidation process.

\section{Selection of the optimum experimental parameters}

Effect of the type of supporting electrolytes and $\mathrm{pH}$ of the solution

Different supporting electrolytes e.g., Britton-Robinson buffer, citrate buffer, and potassium chloride, were tested. It was found that the electrochemical response of pramipexole dihydrochloride was best in a $0.04 \mathrm{M}$ Britton-Robinson buffer.

The effect of $\mathrm{pH}$ on the oxidation of the drug was tested over the $\mathrm{pH}$ range of 2.0 - 11 using cyclic voltammetry (Fig. 2). The peak current increases by increasing $\mathrm{pH}$, until it reaches its maximum at $\mathrm{pH} 6.08$, then decreases; so, a $0.04 \mathrm{M}$ Britton-Robinson buffer of $\mathrm{pH} 6.08$ was selected as the optimum supporting electrolyte. The peak shifted to less positive values with an increased $\mathrm{pH}$, suggesting that the protons are involved in the electrode reaction process. The plot of peak potential versus $\mathrm{pH}$ gives a linear relation in the $\mathrm{pH}$ range of $3.06-$ 10.21 , with a slope of $60 \mathrm{mV}$ per $\mathrm{pH}$ unit.

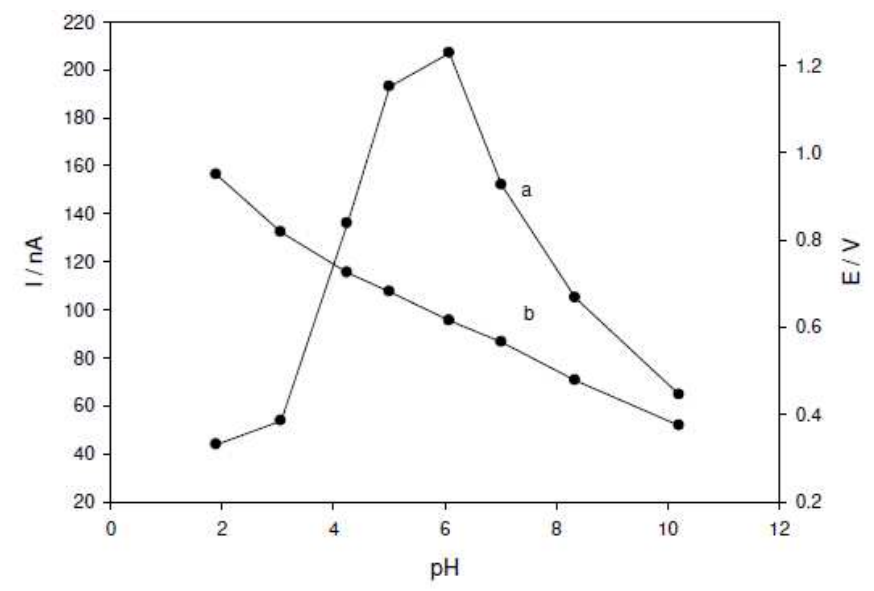

Figure 2. Effect of $\mathrm{pH}$ on the cyclic voltammetric anodic current (a) and peak potential (b) of $9.9 \times 10^{-6} \mathrm{M}$ pramipexole dihydrochloride in a $0.04 \mathrm{M}$ BR buffer.

\section{Effect of pulse amplitude}

The effect of change of pulse amplitude over the range of $10-100 \mathrm{mV}$ on the peak current of $3.98 \times 10^{-6} \mathrm{M}$ pramipexole dihydrochloride was studied. The anodic peak current was increased by increasing the pulse amplitude from 10 to $60 \mathrm{mV}$; then, it remained nearly constant (Fig. 3). So, a $60 \mathrm{mV}$ pulse amplitude was used for further measurements.

\section{Calibration curves, limit of detection and limit of quantification}

Under the optimum parameters, the relation between the anodic differential pulse peak current and the drug concentration was linear in the concentration range of $1.20-8.23 \mu \mathrm{g} / \mathrm{mL}$ of pramipexole dihydrochloride (Fig. 4). The linear relation 
was described by the following regression equation: $\mathrm{I}(\mathrm{nA})=88.99+66.18 \mathrm{C}$ $(\mu \mathrm{g} / \mathrm{mL})$, with a correlation coefficient of 0.9991 . The limit of detection (LOD) and the limit of quantification (LOQ) were calculated by the relation $(\mathrm{k}(\mathrm{SDa}) / \mathrm{b})$ [33], where $\mathrm{k}=3$ for the limit of detection, and 10, in case of the limit of quantification, SDa is the standard deviation of the intercept, and $b$ is the calibration curve slope. The analytical parameters for the calibration graph are shown in Table 1.

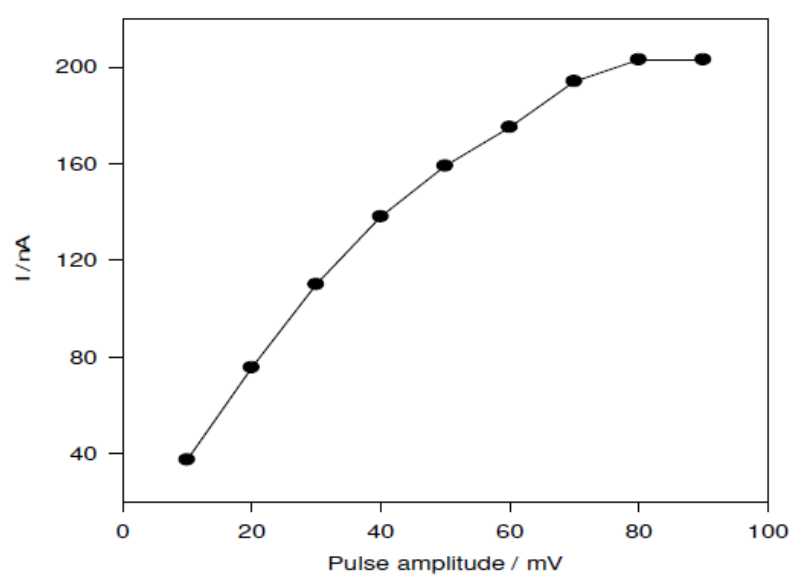

Figure 3. Effect of pulse amplitude on the peak current for $3.98 \times 10^{-6} \mathrm{M}$ pramipexole dihydrochloride in a $0.04 \mathrm{M} \mathrm{BR}$ buffer $\mathrm{pH} 6.08$ and a scan rate of $50 \mathrm{mV} \mathrm{s}^{-1}$.

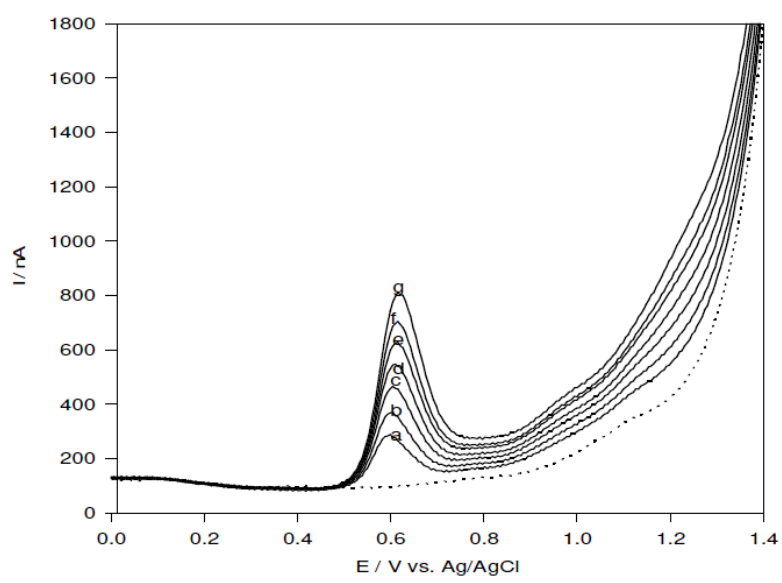

Figure 4. Differential pulse voltammograms for different concentrations of pramipexole dihydrochloride in a $0.04 \mathrm{M}$ Britton-Robinson buffer of $\mathrm{pH} 6.08$, scan rate of $50 \mathrm{mVs}^{-1}$, and pulse amplitude of $60 \mathrm{mV}$ : a, 1.20; b, 2.40; c, 3.58; d, 4.76; e, 5.93; f, 7.09; g, 8.23 $\mu \mathrm{g} / \mathrm{mL}$ pramipexole dihydrochloride. The dotted line represents the blank solution.

Table 1. Analytical parameters of the calibration graph for the determination of pramipexole dihydrochloride using the differential pulse anodic voltammetric method.

\begin{tabular}{|l|c|}
\hline Parameter & \\
\hline Linear range $/ \mu \mathrm{gmL}^{-1}$ & $1.20-8.23$ \\
Slope & 66.18 \\
Intercept & 88.99 \\
Correlation coefficient $(\mathrm{r})$ & 0.9991 \\
$\mathrm{LOD} / \mu \mathrm{gmL}^{-1}$ & 0.21 \\
$\mathrm{LOQ} / \mu \mathrm{gmL}^{-1}$ & 0.68 \\
\hline
\end{tabular}




\section{Reproducibility and robustness}

The intra-day and inter-day (day-to-day) reproducibility, described as RDS, were 1.27 and $2.49 \%(\mathrm{n}=8)$ for $3.98 \times 10^{-6} \mathrm{M}$ of pramipexole dihydrochloride. Small changes in some experimental parameters, e.g., $\mathrm{pH}$ of buffer solution (5.98-6.18), and pulse amplitude (57-63) were tested to evaluate the robustness [33] of the developed method (Table 2). The results indicate that none of the changes significantly affects the recovery of the drug. This provides an indication about the reliability of the method, and the proposed method could be considered robust.

Table 2. Robustness results of the proposed method.

\begin{tabular}{|r|c|c|}
\hline \multicolumn{1}{|c|}{ Variable } & Recovery, \% & RSD \\
\hline $\mathrm{pH}=5.98$ & 98.30 & 1.45 \\
6.08 & 98.46 & 0.346 \\
6.18 & 97.99 & 2.58 \\
Pulse amplitude $=57$ & 101.13 & 0.695 \\
60 & 98.46 & 0.346 \\
63 & 99.63 & 0.734 \\
\hline
\end{tabular}

(Average of four determinations)

\section{Interferences}

To prove the selectivity of the method, interferences from excipients usually present in pharmaceutical formulations were tested. The results indicate that no interferences $(<4.8 \%$ change in the oxidation current) were observed in the presence of 100 fold excess of maize starch, magnesium stearate, lactose and talc. So, it can be concluded that the proposed method is sufficiently selective in the determination of the drug, and no previous separations or extractions were needed.

\section{Determination of pramipexole dihydrochloride monohydrate in its Ramixole pharmaceutical formulation}

The developed voltammetric method was proved to be useful in the determination of pramipexole dihydrochloride monohydrate in its Ramixole tablets pharmaceutical formulation. The results are summarized in Table 3.

Table 3. Statistical comparison between the results of Ramixole (1 mg pramipexole dihydrochloride monohydrate / tablet) using the proposed differential pulse voltammetric method and the reference method.

\begin{tabular}{|r|cc|}
\hline Parameters & Proposed DP voltammetric method & $\begin{array}{c}\text { Reference } \\
\text { method [6] }\end{array}$ \\
\hline Mean recovery, \% & 99.04 & 98.25 \\
SD & 0.965 & 0.689 \\
RSD, \% & 0.974 & 0.701 \\
F-ratio (5.41) & 1.962 & \\
t-test (2.306) & 1.522 & \\
\hline
\end{tabular}

The results confirm that there is no interference from the excipients used in the formulation of tablets. The recovery results obtained by the proposed voltammetric method were compared with the published HPLC reference method 
[6]. The results are in good agreement with those obtained from the reference method. Students t- and F-test at 95\% confidence level were applied [34]. The results show that the calculated $\mathrm{t}$ - and F- values did not exceed the tabulated values. There is no significant difference in accuracy or precision between the proposed voltammetric method and the reference HPLC method.

\section{Conclusions}

In this work, the electrochemical behavior of pramipexole dihydrochloride on a carbon paste electrode has been investigated by cyclic and differential pulse voltammetry, and on the basis of this voltammetric behavior differential, a pulse anodic voltammetric procedure was developed for determination of this drug in its pharmaceutical formulation. The proposed voltammetric method shows advantages, such as simple, rapid, low cost, and easy renovation of the carbon paste electrode. The proposed method is less expensive than alternative techniques like HPLC, and hence, it can be applied to routine determination of this drug in quality control laboratories.

\section{References}

1. Sweetman SC. Martindale: the complete drug reference. $36^{\text {th }}$ ed. London: Pharmaceutical Press; 2009.

2. Lau YY, Selenka JM, Hanson GD, et al. J Chromatogr B Biomed Appl. 1996;683:209.

3. Lau YY, Hanson GD, Ichhpurani N. J Chromatogr B Biomed Appl. 1996;683:217

4. Srinubabu G, Jaganbabu K, Sudharani B, et al. Chromatographia. 2006;64:95.

5. Kumar RN, Rao GN, Naidu PY. Der Pharmacia Sinica. 2011;2:125.

6. Panditrao VM, Sarkate AP, Sangshetti JN, et al. J Braz Chem Soc. 2011;22:1253.

7. Deepan T, Paulambethkar K, Vijayalakshmi R, et al. World J Chem. 2012;7:59.

8. Lavudu P, Rani AP, Balashekaran C, et al. Global J Med Res. 2012;12:19.

9. Rajesh NV, Raman D, Durraivel. Int J Pharm Clin Res. 2013;5:17.

10. Chaudhary V, Ubale M. Int J Res Pharm Chem. 2013;3:134.

11. Srikanth KVV, Prasad KRS, Kumar JVS, et al. Der Pharmacia Lettre. 2015;7:94.

12. Murali KN, Ramababu C. World J Pharm Sci. 2015;3:2392.

13. Pawar SM, Dhaneshwar SR. J Liq Chromatogr Related Technol. 2011;34:1664.

14. Hua L, Xiao-Yan C, Xiao-Jin S, et al. Chin J Pharm Anal. 2011;31:30.

15. Rao RN, Sravan B, Ramakrishna K, et al. J Chromatogr B. 2013;932:34.

16. Panchal JG, Patel RV, Menon SK. Biomed Chromatogr. 2011; 25:524.

17. Babu GS, Raju CAI. Asian J Chem. 2007;19:816. 
18. Thangabalan B, Vamsikrishna M, Raviteja NVR, et al. Int J Pharm Pharm Sci. 2011;3:84.

19. Vinodhini C, Sravani MVND, Bhanuprakash M, et al. Int J Res Pharm Biomed Sci. 2011;2:680.

20. Thangabalan B, Kumar DP, Lavanya G, et al. J Pharm Res. 2011;4:813.

21. Pawar DS, Dole MN, Sawant SD. Int J Res Pharm Sci. 2013;4:183.

22. Kumar TV, Seethamma M, Venkateshwarlu G. J Appl Chem. 2014;7:7.

23. Abdel Razeq SA, Abdel Salam KM, Fouad MM, et al. World J Pharm Pharm Sci. 2015;3:1444.

24. Reddy MP, Prabhavthi K. World J Pharm Res. 2015;4:2222.

25. Merey HA, Helmy MI, Tawakkal SM, et al. Port.Electrochim Acta. 2012;30:31.

26. Faridbod F, Jamshidpour T, Ganjali MR, Int J Electrochem Sci. 2016;11:7990.

27. Jain R, Sharma R, Yadav RK, et al. J Electrochem Soc. 2013;160:179.

28. Jain R, Tiwari DC, Shrivastava S. Mater Sci Eng B. 2014;185:53.

29. Narayana PS, Teradal NL, Seetharamappa J, et al. Anal Methods. 2015;7:3912.

30. Palabiyik BB, Uslu B. Ionics. 2016;22:2519.

31. Elyacoubi A, Zayed SIM, Blankert B, et al. Electroanalysis. 2006;18:354.

32. Monk P. Fundamentals of electroanalytical chemistry. New York: Wiley; 2001.

33. Swartz M, Krull IS.Analytical method development and validation. New York: Marcel Dekker Inc; 1997.

34. Miller JC and Miller JN. Statistics for analtical chemistry. 3rd ed. Chichester: Ellis Horwood; 1993. 